J. Dairy Sci. 99:8267-8281

http://dx.doi.org/10.3168/jds.2016-11258

(C) 2016, THE AUTHORS. Published by FASS and Elsevier Inc. on behalf

of the American Dairy Science Association ${ }^{\circledR}$. This is an open access article under

the CC BY-NC-ND license (http://creativecommons.org/licenses/by-nc-nd/3.0/).

\title{
Randomized noninferiority trial comparing 2 commercial intramammary antibiotics for the treatment of nonsevere clinical mastitis in dairy cows
}

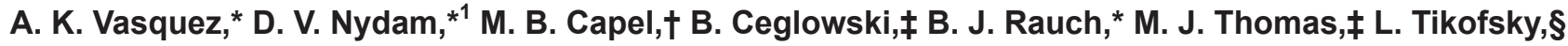 \\ R. D. Watters, ${ }^{*}$ S. Zuidhof, $§$ and M. J. Zurakowski* \\ ${ }^{*}$ Quality Milk Production Services, Department of Population Medicine and Diagnostic Sciences, College of Veterinary Medicine, \\ Cornell University, Ithaca, NY 14853 \\ †Perry Veterinary Clinic, Perry, NY 14530 \\ fDairy Health and Management Services, Lowville, NY 13367 \\ §Boehringer Ingelheim Vetmedica Inc., St. Joseph, MO 64506
}

\section{ABSTRACT}

The purpose was to evaluate 2 intramammary treatments for mild-to-moderate cases of clinical mastitis in a noninferiority comparison. Noninferiority trials are intended to show whether a given treatment, hetacillin potassium, has at least comparable efficacy as the reference treatment, ceftiofur hydrochloride. Treatments can be deemed inferior to the reference treatment by an amount less than the margin of noninferiority, or inconclusive if the confidence interval crosses the margin of noninferiority. Cows with clinical mastitis from 6 farms were considered for enrollment. Using a randomized design, cows with mild or moderate mastitis in 1 quarter were assigned to on-label treatment with either ceftiofur or hetacillin. A total of 596 cows met the criteria needed for continued enrollment. Treatment distribution resulted in 309 cows in the ceftiofur group and 287 cows in the hetacillin group. Mixed regression analysis was performed for the following outcomes: bacteriological cure, pathogen cure, clinical cure, postevent milk production and linear score, and survival to d 30 and 60. Cox proportional hazards analysis was used to describe treatment effect on survival and mastitis risks. Bacteriological cure, defined as absence of causative organism in samples retrieved at $\mathrm{d} 14$ and 21 postmastitis, was similar between groups. No significant statistical differences were found in cure risk, and noninferiority of hetacillin relative to ceftiofur for bacteriological cure was conclusive (hetacillin $=67 \%$, ceftiofur $=72 \%$ ). Absence of a pathogen on both follow-up samples designated a cow as a pathogen cure. Pathogen cure was similar between treatment groups and noninferiority of hetacillin relative to ceftiofur was shown (hetacillin $=$

Received April 1, 2016.

Accepted June 28, 2016.

${ }^{1}$ Corresponding author: dvn2@cornell.edu
$35 \%$, ceftiofur $=32 \%$ ). Clinical cure (hetacillin $=68 \%$, ceftiofur $=64 \%$ ), postevent milk production (hetacillin $=37.0 \mathrm{~kg}$, ceftiofur $=38.2 \mathrm{~kg}$ ), and linear scores (hetacillin $=3.4$, ceftiofur $=3.1$ ) were also not statistically different between treatment groups. Noninferiority of hetacillin relative to ceftiofur was shown for survival to d 30 and survival to d 60 , whereas hetacillin was more likely to have a clinical cure than ceftiofur by d 4. No differences were seen between groups when Cox proportional hazards were performed, neither for exit from the herd in the $60 \mathrm{~d}$ following the event nor in the risk for a subsequent mastitis event. These findings can be used to develop farm-specific protocols for clinical mastitis treatment.

Key words: clinical mastitis, hetacillin, noninferiority, ceftiofur

\section{INTRODUCTION}

The antimicrobial treatment options available to dairy producers for clinical mastitis $(\mathbf{C M})$ are required by United States agencies to exhibit efficacy relative to a nontreated negative control. Very few studies have rigorously compared available treatments to positive controls using appropriate on-farm trials. It would be of benefit to perform controlled trials comparing 2 existing treatments.

In the United States, only 2 classes of antimicrobials are commercially available for intramammary (IMM) treatment of CM: $\beta$-lactams and lincosamides (Baynes and Riviere, 2014). In this study, we compared 2 $\beta$-lactams. Hetacillin potassium (Hetacin K, Boehringer Ingelheim, St. Joseph, MO) is a broad-spectrum IMM antibiotic approved to treat gram-negative and -positive mastitis-causing pathogens such as Streptococcus agalactiae, Streptococcus dysgalactiae, Staphylococcus aureus, and Escherichia coli (FDA, 2010). Hetacillin is chemically related to ampicillin and was shown to 
maintain necessary MIC in a 3 times-per-day milking regimen (Lindquist et al., 2015). Ceftiofur hydrochloride (Spectramast LC, Zoetis, Kalamazoo, MI) is a broadspectrum third-generation cephalosporin indicated to treat mastitis associated with CNS, Strep. dysgalactiae, and E. coli (FDA, 2005). Whereas both drugs have an established milk withdrawal time of $72 \mathrm{~h}$, average length of recommended treatment varies. The label indication for ceftiofur is administration every $24 \mathrm{~h}$ for 2 to $8 \mathrm{~d}$, but the hetacillin label states a 3 -d duration at the same daily interval. The average duration for the use of ceftiofur for mild, moderate, and severe CM was 4.0, 4.4, and $4.5 \mathrm{~d}$ in a recent Wisconsin survey, respectively (Oliveira and Ruegg, 2014).

A 2-sided comparative study must prove a higher defined efficacy for the proposed treatment over the current standard-of-care treatment in a clinical setting with the purpose to reject the null hypothesis that the therapies are not different; if the evidence is not strong enough to favor the tested product, the researcher cannot rule out nor conclude equality. Noninferiority of a therapy is established when the data provide evidence to conclude that its efficacy is within a certain amount of the equivalence margin of the comparison therapy (Walker and Nowacki, 2011). If a researcher can hypothesize and confirm that a therapy is equivalent or superior to the reference, benefits to the patients can include convenience, lower costs, fewer side effects, improved delivery systems, and better integration into a current protocol (Piaggio et al., 2006; Walker and Nowacki, 2011).

With regard to mastitis research, 3 major studies involving Food and Drug Administration-approved IMM preparations have been previously performed as noninferiority trials. Schukken et al. (2013) concluded noninferiority between a first-generation cephalosporin and a third-generation cephalosporin when considering both clinical cure of all nonsevere CM cases and bacteriological cure of gram-positive cases. Their specific interest was to determine any difference in efficacy given that first-generation cephalosporin have limited gram-negative activity whereas third-generation products have broader activity claims (Hornish and Kotarski, 2002; Guerín-Faublee et al., 2003; Pfeifer et al., 2010). The second and third noninferiority trials performed by Arruda et al. (2013) and Johnson et al. (2016) on dry-cow therapy treatments determined noninferiority when considering various indexes, including postcalving new infection risk. No similar comparison has been made between a third-generation cephalosporin, ceftiofur, and a semisynthetic penicillin, hetacillin, in the treatment of mild to moderate CM. A Northeast survey study comparing bacteriological cure rates for 7 mastitis drugs was performed by Wilson et al. (1999). Whereas cure rates for cephapirin rather than ceftiofur were analyzed, hetacillin cure rate was comparable to the cephalosporin product $(62 \%, \mathrm{n}=35 / 56$ vs. $68 \%$, $\mathrm{n}=152 / 222$, respectively). However, given its comparable cure rate, a 2014 study on 51 large dairy herds in Wisconsin indicated that only $3.3 \%(\mathrm{n}=21 / 645)$ of CM cases were treated with IMM hetacillin, whereas $71.6 \%(\mathrm{n}=462 / 645)$ of cases were treated with ceftiofur (Oliveira and Ruegg, 2014).

The current study compared the treatment efficacy of a 3-d administration of IMM hetacillin to a 5-d administration of the reference treatment ceftiofur. The objective of our trial was to evaluate whether noninferiority of the test product against the reference product can be established.

\section{MATERIALS AND METHODS}

\section{Study Design}

This was a randomized noninferiority study. The concept of a noninferiority trial is formalized in the term equivalence margin, which defines a range of values for which the efficacies or margins between differences in clinical outcome are close enough to be considered equivalent (Walker and Nowacki, 2011). A prestated margin of noninferiority is chosen as the smallest value that would show a clinically important effect. This margin is also used in a statement of hypothesis; in our study, the null hypothesis was that a 3 -d treatment with hetacillin is inferior compared with an extended 5 -d treatment with ceftiofur when considering bacteriological cure, clinical cure, pathogen cure, and survival indices. The alternative hypothesis was that a 3 -d treatment with hetacillin is noninferior compared with an extended treatment with ceftiofur by more than the equivalence margin of $15 \%$. The choice of equivalence margins is often less than half of the expected effect in a traditional study. In a trial comparing treatment of gram-negative CM cows, bacteriological cure was $\sim 35 \%$ greater for cows treated with ceftiofur than for cows receiving no treatment (ceftiofur $n=41 / 56$; control $n$ $=18 / 48$; Schukken et al., 2011). Additional assessment of differences in postevent milk production, postevent linear score, and days in the treatment pen (hospital days) was evaluated using traditional hypotheses rather than noninferiority comparisons.

\section{Study Farms}

This trial was conducted between September 2014 and June 2015 at 6 commercial dairy farms in major 
dairy-producing regions of New York State. Farms eligible for inclusion in the study met the following criteria: herd size >500 lactating cows; participation in monthly DHIA testing; accurate recording of CM cases; and willingness to participate and follow standard operating procedures, which included not wavering from treatment plans for $7 \mathrm{~d}$. A known presence of streptococcal CM was also required to ensure appropriate representation of gram-positive and gram-negative etiologies. Medians for this sample of herds were 1,057 lactating cows (range: 524 to 1466), $12,150 \mathrm{~kg} / \mathrm{cow}$ per year of milk (range: 11,773 to $13,091 \mathrm{~kg}$ ), and a bulk tank SCC of 140,500 cells/mL (range: 100,000 to 267,000 cells $/ \mathrm{mL}$ ).

\section{Case Definition}

All cases of CM at each of the 6 Holstein dairies were assessed for enrollment at the time of occurrence. A cow was defined as having $\mathrm{CM}$ if milk was abnormal from one or more quarters. A clinical scoring system (CS) adapted from Wenz et al. (2001) was used to classify CM cases based on severity, and only cows with CS of 1 or 2 were included. Severity of clinical signs was scored as mild $(\mathrm{CS}=1)$, moderate $(\mathrm{CS}=2)$, or severe $(\mathrm{CS}=3)$. A score of 1 was assigned if the milk was visually abnormal; a score of 2 was assigned if the milk was visually abnormal and firmness or swelling of the affected quarter was observed; and a score of 3 was assigned if the milk was grossly abnormal, firmness or swelling of the affected quarter was observed, and signs of systemic disease were present (e.g., fever, dehydration, or depression).

In addition to a $\mathrm{CS}<3$, a cow needed to meet the following criteria: less than 300 DIM, neither CM nor antimicrobial administration in the last $30 \mathrm{~d}$, parity $<6$, only 1 quarter exhibiting signs of CM, and no previous enrollment in the trial.

\section{Treatment Groups}

At each farm location, lactating cows with CM that met the inclusion criteria were randomly allocated to one treatment group via Dairy Comp 305 (DC305, Tulare, CA; 4 farms) or via randomized envelopes containing treatment assignment (2 farms). Treatment groups included a test treatment group consisting of cows receiving 1 treatment of hetacillin once per day for $3 \mathrm{~d}$ into the affected quarter and a reference treatment group consisting of cows receiving 1 treatment of ceftiofur once per day for $5 \mathrm{~d}$ into the affected quarter. Intramammary treatments were administered using partial insertion technique by trained farm personnel.

\section{Timing of Events}

The day of enrollment, also the first day of treatment, was defined as d 1 and commenced upon randomized allocation of treatment group. Before treating a cow, the teat of the affected quarter was thoroughly disinfected and 3 streams of milk from the affected quarter were discarded. A milk sample was taken using aseptic technique and immediately placed in the on-farm freezer. After the sample was taken, the teat end was disinfected again and treated with the allocated treatment. The cow was marked as treated using a leg band, per standard on-farm protocol. For each treatment, a dated and signed treatment confirmation was completed. A CS for cows in both groups was also obtained on d 2 to 5 following the initial score on d 1. Approximately $14 \mathrm{~d}$ $( \pm 4 \mathrm{~d})$ and $21 \mathrm{~d}( \pm 5 \mathrm{~d})$ after the onset of treatment, a milk sample was collected from the enrolled quarter and a CS was determined. Resamples were obtained at least $7 \mathrm{~d}$ apart for each cow. If at any time an animal became systemically ill following randomization and treatment, farm personnel was advised to remove the animal from the study and initiate additional treatments. In these cases, a milk sample and CS were collected before additional treatments were provided. If a cow sustained mastitis in another quarter, it was removed from the trial with the same requirements.

\section{Bacteriological Culture}

Standard culture technique was performed on all samples according to National Mastitis Council guidelines for identification of aerobic organisms (National Mastitis Council, 1999). Briefly, $0.01 \mathrm{~mL}$ of milk was streaked on trypticase soy agar containing $5 \%$ sheep blood and 1\% esculin (PML Microbiologicals, Mississauga, ON, Canada), and plates were incubated aerobically at $37^{\circ} \mathrm{C}$ for 18 to $24 \mathrm{~h}$. After observations of colony morphology and hemolytic patterns, isolates were examined further by means of $3 \%$ potassium hydroxide, Gram staining, catalase and indole testing, and additional biochemical and metabolic evaluations as needed. Gram-negative organisms were identified by colony morphology on MacConkey's agar (Hardy Diagnostics, Santa Maria, CA). Diagnosis and confirmation of IMM infection by culture was based on standard published definitions and assessed at the quarter level. Briefly, an IMM infection was defined as 1 or more colonies isolated from the $10-\mu \mathrm{L}$ milk sample for all pathogens except for CNS. For CNS, 2 or more colonies isolated from the $10-\mu \mathrm{L}$ milk sample were needed to establish presence of an infection (Dohoo et al., 2011). When 2 different types of bacteria were identified, the result was classified as a mixed infection. When at least 
1 colony each of 3 or more of types was isolated, the sample was considered contaminated.

\section{Data Capture}

Sampling and clinical data collection was performed by farm staff ( 5 farms) or a support technician (1 farm). Farm staff was trained by Quality Milk Production Services (Ithaca, NY) personnel and veterinarians to identify mastitis, assign severity scores, enroll cases, collect samples, and complete paper records. Quality assurance audits were performed by Quality Milk Production Services and herd veterinarians and regular visits were performed by the first author.

\section{Sample Size Determination}

The required sample size was determined using the confidence interval approach, considering where the confidence interval for the treatment effect lies with respect to both the margin of noninferiority $(\Delta)$, and a null effect (treatments are equal). Sample size depends on the level of confidence chosen, the risk of Type II error (or desired power), and $\Delta$. Here we specified $\Delta$ as the difference in cure risk ratios between the 2 treatments. A binomial distribution was performed assuming a ceftiofur cure risk of $65 \%$ based on a randomized clinical efficacy trial (Schukken et al., 2011), plotting $\Delta$ as the independent variable and power and sample size as dependent variables. This was used to find the sample size $(\mathrm{n}=250$ per group) with a chosen value for power (0.9) and a chosen value of $\Delta(0.15)$, which is less than half of the expected effect of ceftiofur in a traditional clinical trial (Schukken et al., 2011). The total study size is then twice this number, or 500. We enrolled 600 cows to ensure adequate study power while accounting for loss to follow-up and a Type I error risk of $5 \%$.

\section{Primary and Secondary Outcomes}

Primary outcomes were bacteriological cure, clinical cure, and pathogen cure. A quarter was defined as a bacteriological cure when there was a pathogen present in the pretreatment sample and this pathogen was absent from both posttreatment samples (d 14 and 21). Cows that initially cultured with no growth or contamination were not included in analysis for bacteriological cure. If one of the follow-up samples contained the same organism as the pretreatment sample, the quarter was defined as a noncure. If a cow left the trial due to mastitis reasons and her exit sample revealed the same organism as the pretreatment sample, the quarter was defined as a noncure. If none of the present samples cultured with the enrollment organism, but a cow was missing one or both follow-up samples or a removal sample, the cow was deemed lost to follow-up for bacteriological cure. If none of the present samples cultured with the enrollment organism and one of the samples was contaminated, the cow was also lost to follow-up for this outcome. Samples were missed due to treatment for other ailments, input error, or early dry or sale. If no exit sample was present before the 21-d sample collection period, the cow was lost to follow-up for bacteriological cure. Differences in frequencies of lost to follow-up between treatment groups were noted for each outcome.

A quarter was defined as a clinical cure within the first $5 \mathrm{~d}$ and for the follow-up records when its CS became and remained zero. Clinical cure was dichotomized to include 2 groups: those cows that cured by d 4 and those that did not. Day 1 to 5 trial records were considered sufficient to determine clinical cure.

When both follow-up samples contained no growth, the cow was defined as a pathogen cure. A pathogen did not need to be present in the pretreatment sample to be defined as a pathogen cure. Cows with contaminated samples were lost to follow-up and not considered for pathogen cure analysis. If a cow had 1 of 2 followup samples with no growth but was missing a second sample, the cow was also lost to follow-up.

Secondary outcomes were extended clinical cure, number of clinical days, posttreatment milk production and linear score, survival of the cow in the herd, occurrence of another mastitis event in the same quarter, and hospital days. A quarter was defined as an extended clinical cure when its CS was 0 on d 14 and 21 after the event. The clinical days outcome was defined as the time to clinical cure and was calculated as the number of days from entrance into the treatment pen until clinical signs were undetectable. Hospital days were defined as the number of days (in 24-h intervals), between entrance dates and exit dates into or from the treatment pen. Previous milk production and linear scores (LS) were obtained from the test day data before the event (range: $-8 \mathrm{~d}$ to $-43 \mathrm{~d}$ pre-event). Postevent milk production and LS were obtained from the test day after the event (range: 8 to $43 \mathrm{~d}$ postevent). Linear score is a transformation of SCC, calculated as $[\operatorname{Ln}(\mathrm{SCC} / 100) /$ $\operatorname{Ln}(2)]+3$ (Ali and Shook, 1980). Survival analysis was evaluated by following the cow to dry, cull, or $60 \mathrm{~d}$ postenrollment, whichever came first.

\section{Statistical Analysis}

Noninferiority analysis of binary outcomes was completed using PROC FREQ in SAS version 9.4 (SAS Institute, 2014) with one-sided $95 \%$ confidence intervals 
and noninferiority margins. Statistical analysis of the primary and secondary outcomes was performed using regression models, taking into account the following covariates: parity, DIM, hospital days, previous milk yield, LS, and CM etiology. To select the best model, all possible confounding variables were subjected to bivariate analysis by means of Chi-squared, $t$-tests, or ANOVA tests using PROC FREQ, PROC TTEST, PROC REG, or PROC ANOVA. The primary explanatory variable of interest was treatment group; all interactions with this variable were tested in a similar manner. Any terms with a $P$-value $<0.2$ were offered into the models. Each variable was then examined by manual backward stepwise elimination in the regression until all possible explanatory variables with $P<0.1$ were included. In many of the models, the treatment variable was forced. Farm was first tested as a fixed effect and, if determined not to be significant to the level of $P<0.10$, it was then included as a random effect. This corrected for any within-farm clustering that violated the assumptions of independence. Additionally, basic techniques were used to assess normality, homoscedasticity, and linearity of variables. Transformations were performed and reported as necessary. Not all included animals had complete LS or milk yield data, as some cows experienced the event in early lactation with no prior test day or late in lactation with no post-CM test day. Cows were excluded from hospital days or clinical days analyses if pen moves were not complete in DC305 records. Where analyses were performed on a subgroup of animals, the number of animals with complete data is indicated in the tables.

Mixed logistic regression models were performed for the binary outcomes bacteriological cure, pathogen cure, clinical cure by d 4 , survival to d 30, and survival to d 60. Mixed linear regression models were performed for postevent milk yield and postevent LS. Time in the herd from d 0 to 60 postevent was evaluated using Cox proportional hazards regression (PROC PHREG). Similar analysis was performed to describe the effect of treatment on the survival distribution of quarters experiencing another case of mastitis before 60 d postenrollment.

\section{RESULTS}

\section{Descriptive Results}

Enrollment characteristics for each of the 6 farms are shown in Table 1. In total, the farms experienced 1,168 cases of mastitis, 161 of which were severe $(13.8 \%)$. The number of mastitic cows meeting eligibility criteria was 627. Thirty-one cows did not remain in the study due to secondary treatment of the quarter or cow within the first $7 \mathrm{~d}$ of enrollment $(\mathrm{n}=15$; hetacillin $=12$, ceftiofur $=3$ ), mastitis in another quarter within $7 \mathrm{~d}$ $(\mathrm{n}=8$; hetacillin $=4$, ceftiofur $=4)$, nonsurvival of cow or quarter $(\mathrm{n}=7$; hetacillin $=3$, ceftiofur $=4$ ), and input errors $(\mathrm{n}=1$, ceftiofur). The mean time of first follow-up sample was $14.1 \mathrm{~d}$ postevent $( \pm 1.9 \mathrm{~d}$; $\mathrm{SD}$ ) and second follow-up sample was $21.2 \mathrm{~d}$ postevent $( \pm 2.2 \mathrm{~d})$. Eight cows did not have enrollment samples, but could be assessed for the following outcomes: clinical days, hospital days, postevent milk production and LS, and survival indices. Of the cultures, $63 \%$ produced diagnostic growth $(\mathrm{n}=369 / 588), 31 \%$ resulted in no organism $(n=183 / 588)$, and the remaining $6 \%$ resulted in no significant growth or contamination $(\mathrm{n}=$ $36 / 588)$. Of all etiologies, the most frequently cultured gram-positive organisms found were Strep. dysgalactiae $(14.0 \% ; \mathrm{n}=84 / 588)$ followed by Staph. aureus $(8.0 \% ; \mathrm{n}$ $=47 / 588)$ and Streptococcus uberis $(7.8 \% ; \mathrm{n}=46 / 588)$. Escherichia coli $(13.8 \%$; $\mathrm{n}=81 / 588)$ was the most commonly isolated gram-negative organism, followed by Klebsiella spp. (5.4\%; $\mathrm{n}=32 / 588)$ and Pasteurella spp. $(1.0 \% ; \mathrm{n}=6 / 588)$. All etiologies were evenly distributed $(P>0.05)$ except for Strep. uberis, for which $72 \%(\mathrm{n}=33 / 46)$ of cases were randomly allocated to the ceftiofur group whereas $28 \%(\mathrm{n}=13 / 46)$ were allocated to the hetacillin group $(P<0.01)$. Distribution of organisms within each treatment group can be seen in Table 2.

The distribution of treatments was nearly equivalent; $48 \%$ of cows were assigned to the hetacillin group ( $\mathrm{n}=$ $287 / 596)$ and $52 \%$ of cows were assigned to the ceftiofur group $(\mathrm{n}=309 / 596)$. Distribution of treatment group by farm was also not statistically different $(P=0.68)$. We found no statistical differences in the means of DIM (hetacillin $=130 \mathrm{~d}$, ceftiofur $=129 \mathrm{~d} ; P=0.78$ ), lactation number (hetacillin and ceftiofur $=2.7 ; P=$ 0.46 ), previous test-day LS (hetacillin $=2.3$, ceftiofur $=2.5 ; P=0.37$ ), and milk yields (hetacillin $=42.5 \mathrm{~kg}$, ceftiofur $=42.7 \mathrm{~kg} ; P=0.80)$. The quarter affected did not differ between groups $(P=0.70)$.

\section{Bacteriological Cure}

Cases were not eligible for bacteriological cure when the treated quarter had no growth $(\mathrm{n}=183)$ or contaminated growth $(\mathrm{n}=25)$ on initial culture. If a case did not meet the appropriate collection times for followup samples, it was not included in analysis $(\mathrm{n}=1)$. If a cow had any of the criteria defined in Materials and Methods as lost to follow-up, the cow was not included in analysis $(\mathrm{n}=35)$. The number of cases meeting inclusion criteria was 353: 164 hetacillin-treated cows and 189 ceftiofur-treated cows had complete data. Bacteriological cure was seen in 250 cases (71\%): 112 (68\%) of 
Table 1. Basic description (numbers) of clinical mastitis (CM) cases and enrolled cases on 6 commercial dairy farms $(\mathrm{A}-\mathrm{F})$ in New York during the trial period

\begin{tabular}{lrrrrrrr}
\hline Item & $\mathrm{A}$ & $\mathrm{B}$ & $\mathrm{C}$ & $\mathrm{D}$ & $\mathrm{E}$ & $\mathrm{F}$ & Total \\
\hline Total CM cases & 110 & 335 & 138 & 198 & 168 & 219 & 1,168 \\
Total nonsevere CM cases & 94 & 226 & 132 & 183 & 161 & 211 & 1,007 \\
Number meeting eligibility criteria & 74 & 130 & 84 & 105 & 129 & 105 & 627 \\
Number of cases maintaining enrollment & 71 & 119 & 78 & 99 & 125 & 104 & 596 \\
Hetacillin & 28 & 55 & 40 & 50 & 62 & 52 & 287 \\
Ceftiofur & 43 & 64 & 38 & 49 & 63 & 52 & 309 \\
Culture results (pretreatment) & & & & & & & \\
No growth & 30 & 53 & 11 & 18 & 40 & 31 & 183 \\
Gram-positive & 17 & 29 & 48 & 44 & 43 & 41 & 222 \\
Gram-negative & 8 & 17 & 8 & 35 & 29 & 16 & 113 \\
Other & 16 & 20 & 11 & 2 & 13 & 16 & 78 \\
\hline
\end{tabular}

${ }^{1}$ Culture results falling into this category are defined in Table 2 .

the hetacillin cows and $138(73 \%)$ of the ceftiofur cows. Differences in bacteriological cure percentages based on etiology and treatment group can be seen in Figures 1 and 2 .

When stratified by Gram stain classification, 74 of $106(70 \%)$ ceftiofur-treated cows with gram-positive mastitis cured whereas 57 of $90(63 \%)$ of hetacillin cows with gram-positive cultures experienced bacteriological cure. Of the cows with gram-negative mastitis, $82 \%$ of the ceftiofur group cured $(\mathrm{n}=49 / 60)$ whereas a similar percentage $(79 \%)$ of the hetacillin group cured $(\mathrm{n}=$ $42 / 53)$.

Mixed model logistic regression of bacteriological cure produced a model that included etiology and treatment

Table 2. Distribution of organisms between treatment groups for pretreatment samples

\begin{tabular}{|c|c|c|}
\hline Organism & $\begin{array}{l}\text { Hetacillin, no. } \\
\quad(\mathrm{n}=282)\end{array}$ & $\begin{array}{c}\text { Ceftiofur, no. } \\
(\mathrm{n}=306)\end{array}$ \\
\hline No growth & 95 & 88 \\
\hline No significant growth ${ }^{1}$ & 17 & 11 \\
\hline Escherichia coli & 36 & 45 \\
\hline Klebsiella spp. & 17 & 15 \\
\hline Streptococcus dysgalactiae & 47 & 37 \\
\hline Streptococcus uberis & 13 & 33 \\
\hline CNS & 5 & 6 \\
\hline Staphylococcus aureus & 21 & 26 \\
\hline Other cocci ${ }^{2}$ & 20 & 26 \\
\hline Other Enterobacteriaceae & 6 & 2 \\
\hline Other organisms & 21 & 29 \\
\hline Pseudomonas spp. ${ }^{1}$ & 0 & 1 \\
\hline Pastuerella & 1 & 5 \\
\hline Proteus spp. & 0 & 1 \\
\hline Yeast $^{1}$ & 4 & 8 \\
\hline Prototheca spp. ${ }^{1}$ & 1 & 0 \\
\hline Trueperella pyogenes ${ }^{1}$ & 3 & 5 \\
\hline Gram-positive bacillus & 1 & 1 \\
\hline Contamination $^{1}$ & 0 & 2 \\
\hline Missing sample $^{1}$ & 5 & 3 \\
\hline
\end{tabular}

${ }^{1}$ Included in other category of Table 1.

${ }^{2}$ Includes non-Strep. uberis/non-Strep. dysgalactiae, Streptococcus spp., Enterococcus spp., and Lactococcus spp. group as explanatory variables (Table 3 ). Interactions between treatment group and etiology were assessed, but any observed interactions were likely due to chance assuming the null hypothesis was true. When controlling for treatment, odds of bacteriological cure for all CM organisms, except for Staph. aureus, were higher than the grouping of other organisms that included Pseudomonas, yeast, Prototheca, Corynebacterium, and Enterococcus. These increased odds were statistically significant for E. coli and Strep. dysgalactiae. The odds ratio (OR) for bacteriological cure between treatment groups was approximately 1.3 times higher for ceftiofur-treated cows compared with hetacillin-treated cows (95\% CI: $0.77-2.1, P=0.32$ ). Least squares means for bacteriological cure for hetacillin-treated cows was $67 \%$ (95\% CI: $59-75 \%$ ), whereas it was $72 \%$ for ceftiofurtreated cows (95\% CI: $65-79 \%$ ).

Calculation of point estimates for cure risk differences can be seen in Figure 3. The risk difference between the groups was -0.047 , with a $95 \%$ confidence interval of -0.14 to 0.048 . When stratified by Gram staining classification $(\mathrm{n}=309$; gram-positives $\mathrm{n}=$ 196, gram-negatives $\mathrm{n}=113$ ), a larger risk difference was seen in the gram-positive organisms $(-0.065 ; 95 \%$ CI: -0.197-0.068). The risk difference was least negative for gram-negative etiologies at -0.024 (95\% CI: $-0.171-0.122)$

\section{Clinical Cure}

A total of 572 cows met the criteria necessary to assess this outcome (hetacillin $=268$, ceftiofur $=304$ ). Of the initial 596 cows, 24 cows did not have scores recorded for the required 5 sequential days and were not included in analysis. Overall, $64 \%$ of cows experienced $\leq 4$ clinical days $(\mathrm{n}=366 / 572)$. Of the hetacillin-treated cows, $70 \%$ experienced $\leq 4$ clinical days $(\mathrm{n}=187 / 268)$ whereas $59 \%$ of ceftiofur-treated cows experienced $\leq 4$ 
clinical days $(\mathrm{n}=179 / 304 ; P=0.007)$. A noninferiority analysis calculated a proportion difference of $0.12(95 \%$ CI: 0.031-0.19; Figure 3.).

A mixed binomial logistic regression model including treatment group and log of hospital days resulted in similar least squares means of clinical cure for each group (68\% for hetacillin, $64 \%$ for ceftiofur). A total of 352 cows with full data were included in regression analysis. The effects of treatment group were not statistically significant in the model $(P=0.65)$. When hospital days were included, the odds ratio of having $\leq 4$ clinical days for hetacillin-treated cows versus ceftiofur-treated cows, although higher (1.2), was not significantly different from 1 (95\% CI: $0.62-2.2 ; P=$ $0.57)$. As interpreted, an increase in hospital days leads to a decrease in the log-odds for the outcome of clinical days $\leq 4$.

\section{Pathogen Cure}

Absence of a pathogen on both follow-up samples designated a cow as a pathogen cure. To be considered a pathogen cure, both follow-up samples as well as the enrollment sample had to be present and not contaminated (missing, $\mathrm{n}=23$; contaminated, $\mathrm{n}=39$ ). If a cow had any of the criteria defined in Materials and Methods as lost to follow-up, it was not included in analysis $(\mathrm{n}=11)$. If a case did not meet the appropriate collection times for follow-up samples, the case was not included in analysis $(\mathrm{n}=2)$. A total of 521 cows were used in the analysis (ceftiofur $=271$, hetacillin $=$ 250) and 462 cows had full data for modeling. A cow with a no growth or growth result upon enrollment had to maintain a no growth result in both of its follow-up samples to be considered a pathogen cure. Overall, $44 \%$ of cows experienced a pathogen cure: $45 \%$ of hetacillintreated cows and $43 \%$ of ceftiofur-treated cows. Mixed model logistic regression resulted in a numerically better pathogen cure $(\mathrm{OR}=1.1)$ for hetacillin-treated cases as compared with the ceftiofur cases, but the observed difference was likely due to chance $(P=0.57)$. Least squares means for hetacillin-treated cows was $35 \%$ in the model whereas $32 \%$ cured for ceftiofur (95\% CI: hetacillin $=22-50 \%$; ceftiofur $=20-47 \%$ ). Variables significant in the model were etiology, previous LS, and previous milk yield (Table 4).

No growth results were exempt from the analysis described by Table 3 . However, the effects of this etiology were reflected in the logistic model for pathogen cure: when all other variables were held constant, odds of

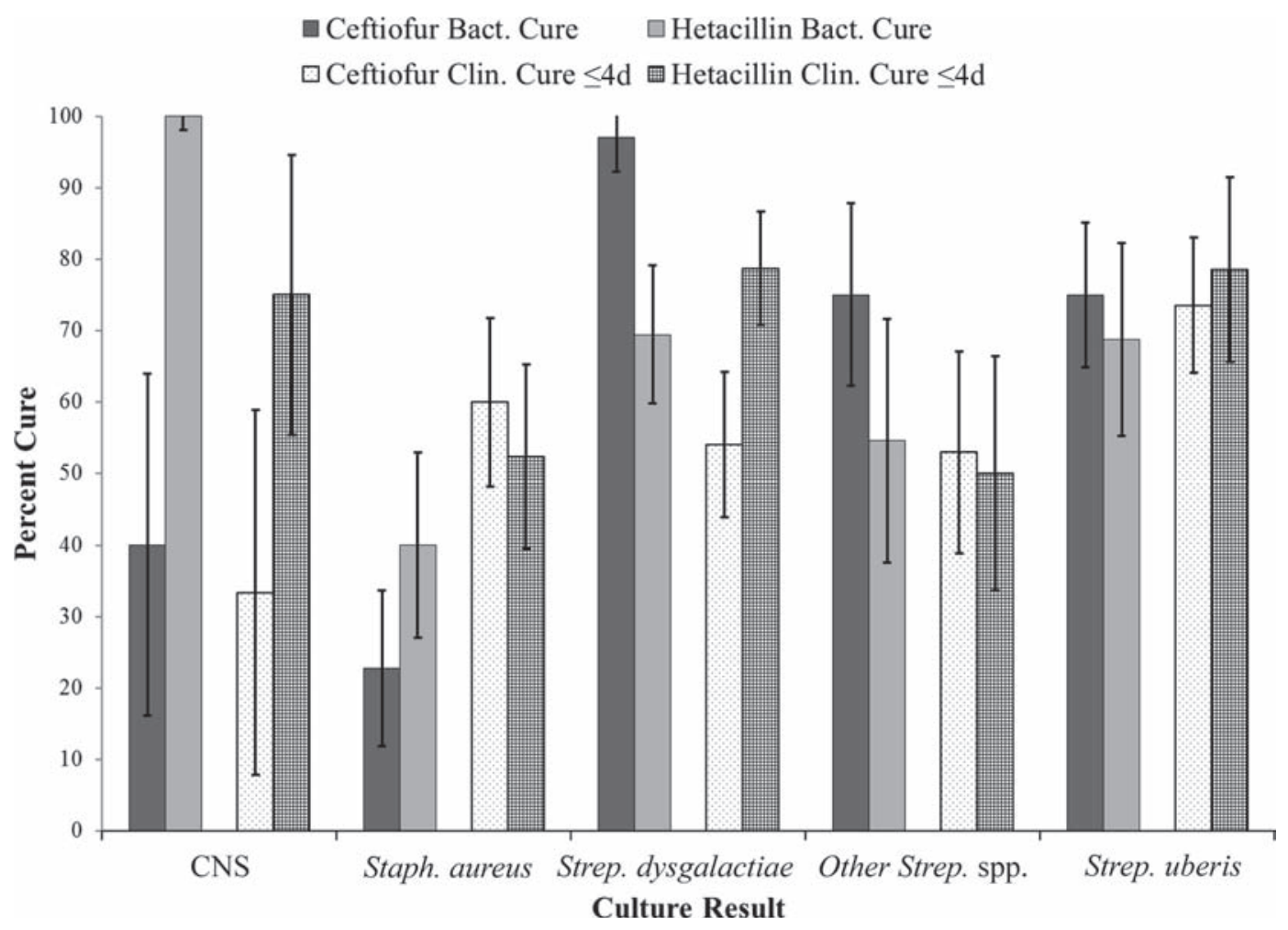

Figure 1. Bacteriological (Bact.) and clinical (Clin.) cure percentages for the following mastitis etiologies on aerobic culture: Staphylococcus aureus, Streptococcus dysgalactiae, Streptococcus uberis, and other streptococcal organisms. Error bars indicate $95 \%$ CI based on SE of the mean proportion. 


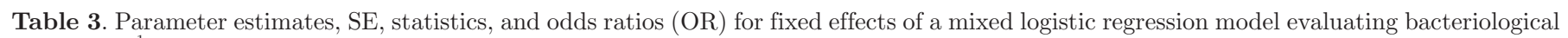
cure $=\operatorname{true}^{1}(\mathrm{n}=353)$

\begin{tabular}{|c|c|c|c|c|c|c|}
\hline Parameter & Description & Estimate & $\mathrm{SE}$ & $P$-value & $\mathrm{OR}$ & $95 \% \mathrm{CI}$ \\
\hline Intercept & & 0.79 & 0.28 & 0.037 & & \\
\hline \multirow[t]{2}{*}{ Treatment } & Hetacillin & -0.25 & 0.26 & 0.32 & 0.78 & $0.47-1.3$ \\
\hline & Ceftiofur & Referent & & & & \\
\hline \multirow[t]{7}{*}{ Etiology } & Streptococcus uberis & 0.28 & 0.42 & 0.50 & 1.3 & $0.58-3.0$ \\
\hline & Streptococcus spp. & 0.0065 & 0.48 & 0.99 & 1.0 & $0.39-2.6$ \\
\hline & Streptococcus dysgalactiae & 0.92 & 0.41 & 0.024 & 2.5 & $1.1-5.6$ \\
\hline & Staphyloccus aureus & -1.48 & 0.42 & 0.0005 & 0.23 & $0.10-0.52$ \\
\hline & Klebsiella spp. & 0.11 & 0.48 & 0.82 & 1.1 & $0.44-2.9$ \\
\hline & Escherichia coli & 1.4 & 0.45 & 0.0023 & 4.0 & $1.6-9.7$ \\
\hline & Other $^{2}$ & Referent & & & & \\
\hline
\end{tabular}

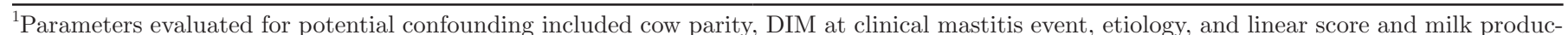
tion at test day previous to event. Farm was included as a random effect but had no contribution to variance.

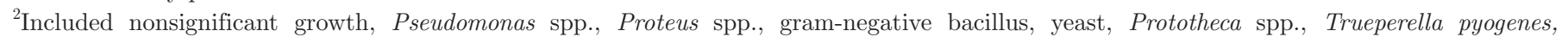
Corynebacterium spp., Enterobacter spp., and Enterococcus spp.

pathogen cure for all etiologies except for $E$. coli were trending lower or significantly lower than no growth results, indicating that cows experiencing a no growth result were likely to remain no growth at both resample dates. Whereas E. coli CM had an increased odds of pathogen cure, it was not statistically significant $(P=$ $0.93)$. Interactions between treatment group and etiol- ogy were assessed but not statistically significant to the level of $P<0.05$. As milk yield or LS increased, the odds of pathogen cure decreased.

Point estimates for pathogen cure risk differences with confidence intervals can be seen in Figure 3. The risk difference between the groups was 0.020 , with a $95 \%$ confidence interval of -0.065 to 0.11 .

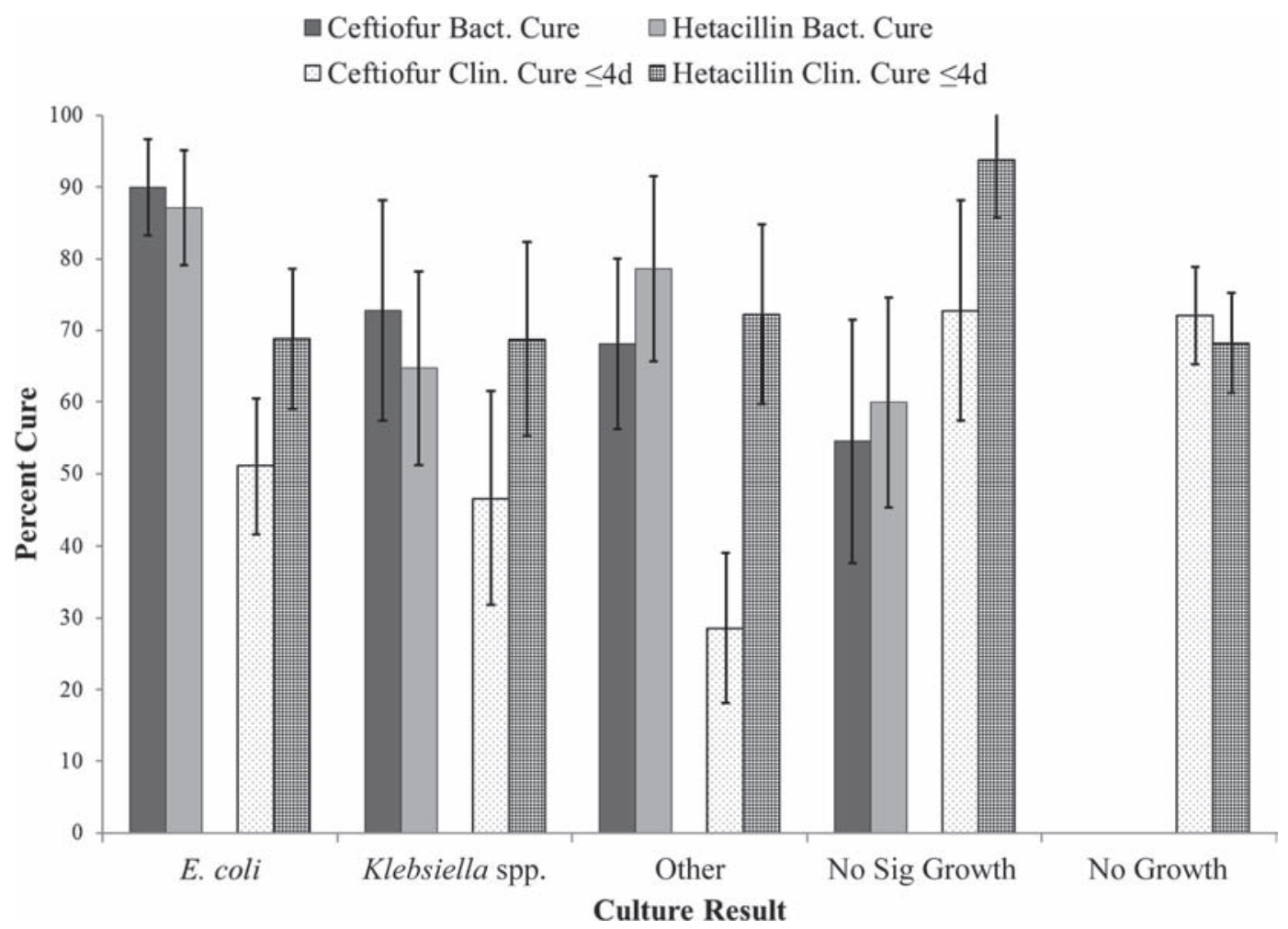

Figure 2. Bacteriological (Bact.) and clinical (Clin.) cure percentages for the following mastitis etiologies on aerobic culture: Escherichia coli, Klebsiella spp., and other, defined as Pseudomonas spp., Proteus spp., gram-negative bacillus, yeast, Prototheca spp., Trueperella pyogenes, Corynebacterium spp., Enterobacter spp., and Enterococcus spp. No significant (Sig) growth and no growth also included. Cows with no growth results were not included in bacteriological cure analysis. Error bars indicate 95\% CI based on SE of the mean proportion. 
Table 4. Parameter estimates, SE, statistics, and odds ratios (OR) for fixed effects of a mixed logistic regression model evaluating pathogen cure $=\operatorname{true}^{1}(\mathrm{n}=462)$

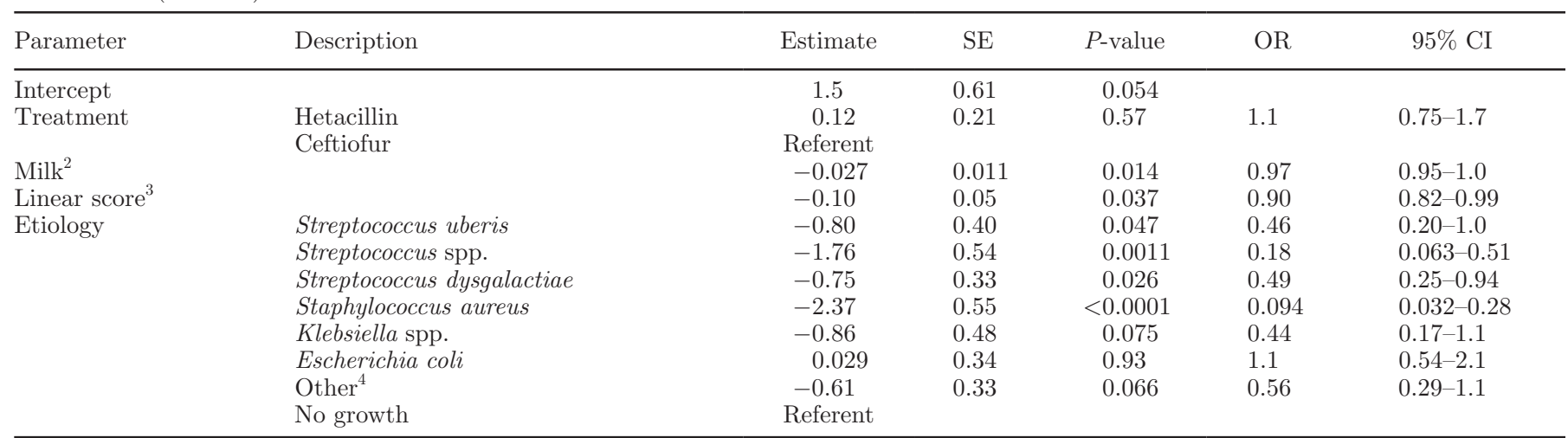

${ }^{1}$ Parameters evaluated for potential confounding included cow parity, DIM at clinical mastitis event, etiology, and linear score and milk production at test day previous to event. Farm was included as a random effect.

${ }^{2}$ Milk production $(\mathrm{kg})$ on test $\mathrm{d} 8$ to $43 \mathrm{~d}$ before clinical mastitis event.

${ }^{3}$ Linear score on test d 8 to 43 d before clinical mastitis event.

${ }^{4}$ Included nonsignificant growth, Pseudomonas spp., Proteus spp., gram-negative bacillus, yeast, Prototheca spp., Trueperella pyogenes, Corynebacterium spp., Enterobacter spp., and Enterococcus spp.

\section{Extended Clinical Cure and Clinical Days}

Using resample CS at $\mathrm{d} 14 \pm 4$ and $21 \pm 5(\mathrm{n}=$ $520)$, bivariate analysis shows $92 \%(\mathrm{n}=221 / 241)$ of hetacillin-treated cows with clinical cure and $91 \%$ (n $=253 / 279$ ) of ceftiofur-treated cows with clinical cure. A Chi-squared comparison indicates no differences between treatment groups $(P=0.68)$. Noninferiority

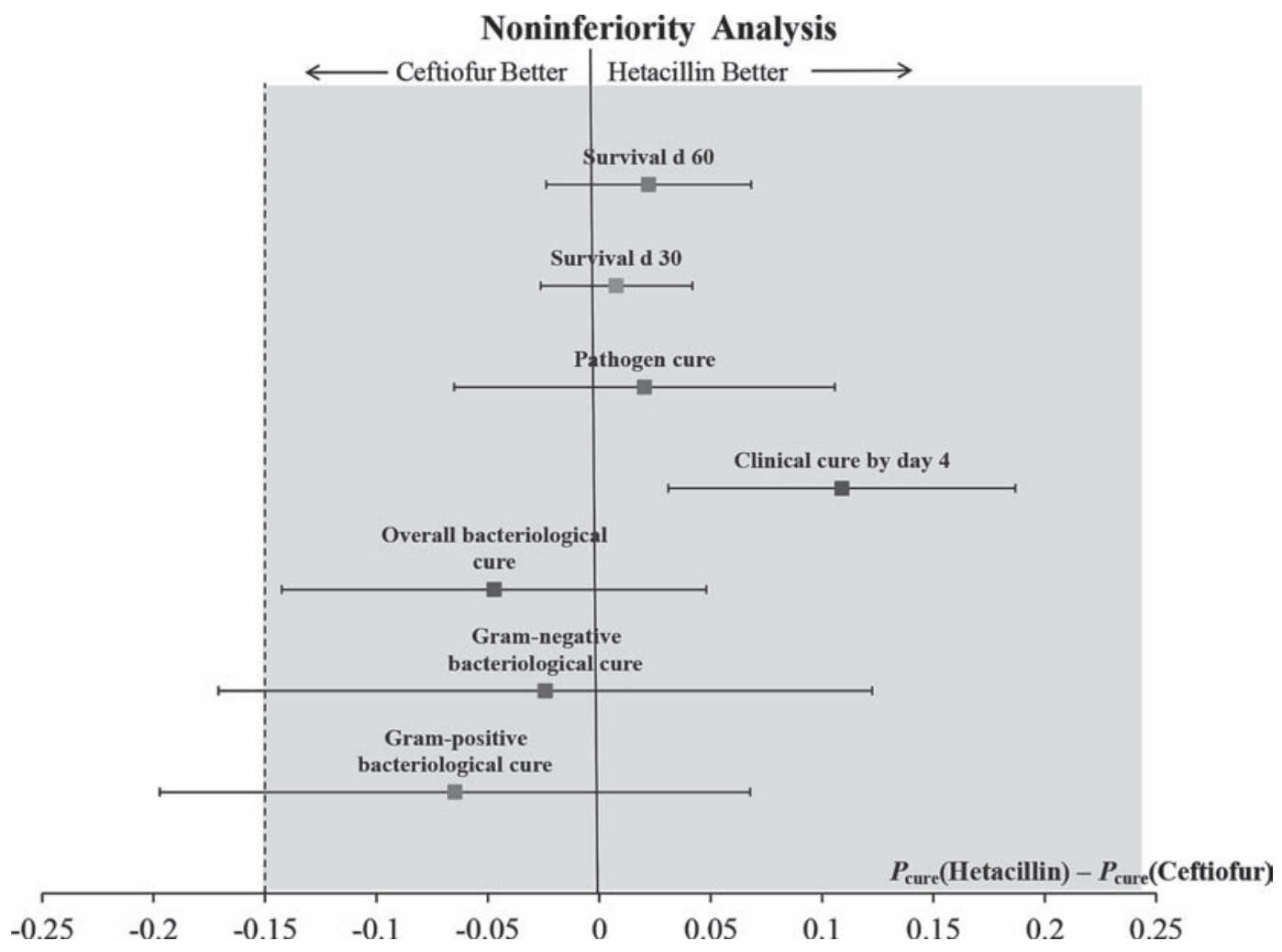

Figure 3. Representation of outcome probability differences for hetacillin versus ceftiofur in a noninferiority comparison. The gray boxes represent the point estimates for each difference. Arrowheads indicate a 95\% CI. Shaded area is representative of noninferiority. Intervals falling in the area $>0$ conclude superiority of hetacillin to ceftiofur. Values crossing -0.15 (the noninferiority margin) are inconclusive. Overall bacteriological cure $=$ all etiologies. Pathogen cure $\left(P_{\text {cure }}\right)$ is defined as absence of a pathogen on both follow-up samples $(\mathrm{d} 14$ and 21$)$. 
Table 5. Parameter estimates, SE, statistics, and LSM for fixed effects of a mixed linear regression model evaluating postevent milk production $(\mathrm{kg})^{1}(\mathrm{n}=484)$

\begin{tabular}{|c|c|c|c|c|c|c|}
\hline Parameter & Description & Estimate & SE & $P$-value & $\operatorname{LSM}(\mathrm{kg})$ & $95 \%$ CI \\
\hline \multirow[t]{2}{*}{ Treatment } & \multirow{2}{*}{$\begin{array}{l}\text { Hetacillin } \\
\text { Ceftiofur }\end{array}$} & -1.2 & 0.68 & 0.091 & 37.0 & $35.9-38.2$ \\
\hline & & Referent & & & 38.2 & $37.1-39.3$ \\
\hline \multirow[t]{3}{*}{ Days in milk } & $1-100$ & 10.2 & 0.92 & $<0.0001$ & 43.0 & $41.8-44.3$ \\
\hline & $101-200$ & 4.2 & 0.89 & $<0.0001$ & 37.0 & $35.8-38.2$ \\
\hline & $>200$ & Referent & & & 32.8 & $31.3-34.3$ \\
\hline \multirow{6}{*}{ Etiology } & Streptococcus dysgalactiae & -3.2 & 1.1 & 0.0033 & 36.5 & $34.6-38.3$ \\
\hline & Staphylococcus aureus & -1.8 & 1.4 & 0.18 & 37.8 & $35.4-40.3$ \\
\hline & Klebsiella spp. & -1.4 & 1.6 & 0.39 & 38.3 & $35.4-41.2$ \\
\hline & Escherichia coli & -4.2 & 1.1 & 0.0002 & 35.4 & $33.6-37.3$ \\
\hline & Other $^{3}$ & -3.3 & 1.1 & 0.0026 & 36.4 & $34.5-38.2$ \\
\hline & No growth & Referent & & & 39.7 & $38.4-40.9$ \\
\hline
\end{tabular}

${ }^{1}$ Within 8 to 43 d postevent. Parameters evaluated for potential confounding included cow parity, DIM at clinical mastitis event, etiology, and linear score and milk production at test day previous to event. Farm was included as a random effect.

${ }^{2}$ Milk production $(\mathrm{kg})$ at previous test-date ( $8-43 \mathrm{~d}$ premastitis event).

${ }^{3}$ Included nonsignificant growth, Pseudomonas spp., Proteus spp., gram-negative bacillus, yeast, Prototheca spp., Trueperella pyogenes, Corynebacterium spp., Enterobacter spp., and Enterococcus spp.

analysis confirms that the treatments are noninferior when assessing this outcome (risk difference $=0.010$, 95\% CI: $-0.039-0.059$ ).

Any cow experiencing 5 or more clinical days was given a value of 5 . Bivariate analysis indicated a difference in clinical days between treatment groups $(P$ $=0.0026$ ), with the hetacillin-treated cows experiencing overall less days $(3.4 \mathrm{~d}$; 95\% CI: $1.3-1.5)$ versus ceftiofur-treated cows (3.7 d; 95\% CI: 1.3-1.5). Lack of normality of clinical days did not permit linear regression modeling.

\section{Postevent Milk Yield}

All cows with milk yield values at 8 to $43 \mathrm{~d}$ postmastitis event were included in the analysis. The mean number of days between mastitis event and test date for data retrieval was $23.6 \mathrm{~d}$ with a median of $24 \mathrm{~d}$. The total number of included cows was 542, with 261 in the hetacillin group and 281 in the ceftiofur group. Average postevent milk yield between the groups was similar; the average test-day milk for hetacillin-treated cows was $38.2 \mathrm{~kg}$ whereas the average milk for ceftiofurtreated cows was $38.7 \mathrm{~kg}$ (bivariate analysis, $P=0.54$ ). A mixed linear regression model used 484 observations and included DIM category, previous test-day milk yield, and etiology. The least squares means for hetacillin-treated and ceftiofur-treated cows were 37.0 and $38.2 \mathrm{~kg}$, respectively $(P=0.09)$. In the model, as expected, as previous milk yield increased, postevent milk yield increased. Cows lower in DIM had significantly greater milk production than those $>200$ DIM, and the least squares means for milk yield decreased with increasing DIM category. All etiology groups had lower milk production than those with no growth results (Table 5).

\section{Postevent LS}

All cows with LS values at 8 to $43 \mathrm{~d}$ postmastitis event were assessed for analysis $(\mathrm{n}=531$; hetacillin $=251$, ceftiofur $=280$ ). The mean number of days between mastitis event and test date for data retrieval was $23.6 \mathrm{~d}$ with a median of $24 \mathrm{~d}$. Average postevent LS for hetacillin-treated cows and ceftiofur-treated cows were 3.4 and 3.1 , respectively (bivariate analysis, $P=$ 0.66). A mixed linear regression model included previous LS, parity, and etiology. The least squares means for hetacillin-treated and ceftiofur-treated cows were 3.4 and 3.1 , respectively $(P=0.086)$. A total of 466 cows were included in the model. As expected, previous LS was significant in the model; as previous LS increased, postevent LS increased. In the model, each earlier parity had a lower LS than the third and greater parity when other variables were accounted for $(P=$ 0.0032). All culture results had higher LS than those cows culturing with no growth results. $P$-values and least squares means for each etiology can be found in Table 6.

\section{Survival to $d 30$}

A cow not surviving was defined as having experienced culling or death. A total of 585 cows were included in the analysis: 284 hetacillin-treated cows and 301 ceftiofur-treated cows. Overall, $95 \%$ of cows sur- 
Table 6. Parameter estimates, SE, statistics, and LSM for fixed effects of a mixed linear regression model evaluating postevent linear score $(\mathrm{LS})^{1}(\mathrm{n}=466)$

\begin{tabular}{|c|c|c|c|c|c|c|}
\hline Parameter & Description & Estimate & $\mathrm{SE}$ & $P$-value & LSM & $95 \% \mathrm{CI}$ \\
\hline \multirow{2}{*}{ Treatment } & \multirow{2}{*}{$\begin{array}{l}\text { Hetacillin } \\
\text { Ceftiofur }\end{array}$} & 0.36 & 0.21 & 0.086 & 3.4 & $3.0-3.8$ \\
\hline & & Referent & & & 3.1 & $2.7-3.5$ \\
\hline \multirow[t]{3}{*}{ Parity } & 1 & -0.85 & 0.31 & 0.0064 & 2.9 & $2.3-3.5$ \\
\hline & 2 & -0.64 & 0.23 & 0.0065 & 3.1 & $2.7-3.6$ \\
\hline & $\geq 3$ & Referent & & & 3.8 & $3.4-4.1$ \\
\hline \multirow{6}{*}{ Etiology } & Streptococcus dysgalactiae & 0.76 & 0.33 & 0.024 & 3.3 & $2.8-3.9$ \\
\hline & Staphylococcus aureus & 1.8 & 0.44 & $<0.0001$ & 4.3 & $3.5-5.1$ \\
\hline & Klebsiella spp. & 0.69 & 0.48 & 0.15 & 3.3 & $2.4-4.2$ \\
\hline & Escherichia coli & 0.60 & 0.35 & 0.085 & 3.2 & $2.6-3.8$ \\
\hline & Other $^{3}$ & 0.68 & 0.33 & 0.039 & 3.3 & $2.7-3.8$ \\
\hline & No growth & Referent & & & 2.6 & $2.1-3.0$ \\
\hline
\end{tabular}

${ }^{1}$ Within 8 to 43 d postevent. Parameters evaluated for potential confounding included cow parity, DIM at clinical mastitis event, etiology and LS and milk production at test day previous to event. Farm was included as a random effect.

${ }^{2}$ Linear score at previous test-date (8-43 d premastitis event).

${ }^{3}$ Included nonsignificant growth, Pseudomonas spp., Proteus spp., gram-negative bacillus, yeast, Prototheca spp., Trueperella pyogenes, Corynebacterium spp., Enterobacter spp., and Enterococcus spp.

vived to $\mathrm{d}$ 30. Of the hetacillin-treated cows, $12(4.2 \%)$ did not survive to $30 \mathrm{~d}$ compared with $15(5.0 \%)$ of ceftiofur-treated cows. In a mixed logistic regression model with 521 observations, the odds of survival were higher in the hetacillin group $(\mathrm{OR}=1.2)$, but treatment group was not statistically significant $(P=0.73)$. The only significant variable was previous milk yield $(P$ $=0.022$ ), which showed an increased odds of survival with increasing previous milk yield $(\mathrm{OR}=1.05 ; 95 \%$ CI: 1.01-1.1). Noninferiority analysis resulted in a risk difference of 0.0076 (95\% CI: $-0.026-0.042$; Figure 3).

\section{Survival to d 60}

The same cow inclusions were made as for survival to $\mathrm{d} 30(\mathrm{n}=585$; hetacillin $=284$; ceftiofur $=301)$. Overall, $91 \%$ of cows survived to d 60 . Of the hetacillintreated cows, $22(7.8 \%)$ did not survive to $60 \mathrm{~d}$ compared with $30(10.0 \%)$ of the ceftiofur-treated cows. In a mixed logistic regression model, the odds of survival were higher in the hetacillin group $(\mathrm{OR}=1.4)$ but the $P$-value was 0.26 . In the model, the odds of survival increased as previous milk yield increased $(\mathrm{OR}=1.04$; 95\% CI: $1.01-1.07 ; P=0.012)$. The risk difference was 0.022 (95\% CI: $-0.024-0.068$; Figure 3).

\section{Time-to-Event: Survival Analysis and Mastitis Recurrence}

The same cows included in logistic analysis of survival to 30 and $60 \mathrm{~d}$ were included in the time-toevent analysis for overall survival $(\mathrm{n}=585$; hetacillin
$=284 ;$ ceftiofur $=301)$. A total of 521 observations were included in Cox proportional hazards regression. Modeling for overall survival in time-to-event analysis provided a hazard ratio of 0.74 when comparing hetacillin- to ceftiofur-treated cows, indicating a reduction in risk of $26 \%$ for that group. The treatment group $P$-value was 0.27 . The only variables that remained in the model were parity $(P=0.086)$ and previous milk yield $(P=0.0010)$.

Modeling for time-to-mastitis event in the same quarter provided a hazard ratio for the hetacillin group over the ceftiofur group of $1.1(P=0.73)$ when controlling for milk yield. One farm did not reliably record mastitis at the quarter level, leading to removal of 104 cows from analysis. Three cows were not included because their quarter ceased production within $7 \mathrm{~d}$ of enrollment. The total number of cows eligible for analysis was 478 (hetacillin $=229$; ceftiofur $=249$ ). A total of 421 observations were included in a Cox proportional hazards regression model. Only previous milk yield was significant in the model $(P=0.0004)$.

\section{Hospital Days}

A cow was eligible for hospital days analysis when a pen move occurred, indicating exit from the treatment pen in both DC305 and the written record $(\mathrm{n}=351)$. Four of 6 of the dairies reliably recorded pen moves; cows enrolled from 2 of the dairies did not contribute to analysis of this outcome. The number of cows meeting criteria was 344 (hetacillin $=164$; ceftiofur $=180$ ). Data were normalized using the log of hospital days 
Table 7. Parameter estimates, SE, statistics, and LSM of a mixed linear regression model evaluating $\log (\text { hospital days })^{1}(\mathrm{n}=344)$

\begin{tabular}{|c|c|c|c|c|c|c|}
\hline Parameter & Description & Estimate & SE & $P$-value & $\operatorname{LSM}(\mathrm{d})$ & $95 \% \mathrm{CI}$ \\
\hline \multirow[t]{2}{*}{ Treatment } & Hetacillin & -0.26 & 0.03 & $<0.0001$ & 6.2 & $4.7-8.1$ \\
\hline & Ceftiofur & Referent & & & 8.0 & $6.1-10.4$ \\
\hline \multirow{5}{*}{ Etiology } & Streptococcus spp. & 0.11 & 0.072 & 0.11 & 7.4 & $5.6-10.0$ \\
\hline & Streptococcus dysgalactiae & 0.087 & 0.058 & 0.14 & 7.23 & $5.5-9.6$ \\
\hline & Staphylococcus aureus & 0.22 & 0.062 & 0.0004 & 8.3 & $6.2-11.0$ \\
\hline & Other $^{2}$ & -0.0025 & 0.054 & 0.96 & 6.6 & $5.0-8.7$ \\
\hline & No growth & Referent & & & 6.6 & $5.1-8.7$ \\
\hline
\end{tabular}

${ }^{1}$ Parameters evaluated for potential confounding included cow parity, DIM at clinical mastitis event, etiology, and linear score and milk production at test day previous to event. Farm was included as a random effect.

${ }^{2}$ Included nonsignificant growth, Pseudomonas spp., Proteus spp., gram-negative bacillus, yeast, Prototheca spp., Trueperella pyogenes, Corynebacterium spp., Enterobacter spp., and Enterococcus spp.

as the outcome. Bivariate analysis revealed a greater number of hospital days for the ceftiofur-treated group $(8.0 \mathrm{~d})$ versus the hetacillin-treated group $(6.2 \mathrm{~d} ; P$ $<0.001)$. A mixed linear regression model included etiology as the only significant covariate, but values for least squares means remained constant (ceftiofur $=8.0$ $\mathrm{d}$, hetacillin $=6.2 \mathrm{~d} ; P<0.001$ ). Table 7 describes the model of $\log$ of hospital days. On average, all etiologies aside from Klebsiella spp. and other experienced more hospital days than no growth cows. Using no growth as the base in the model, only Staph. aureus differed statistically in hospital days.

\section{DISCUSSION}

Using a noninferiority comparison, our study evaluated the efficacy of 2 IMM antibiotic preparations for the treatment of mild to moderate CM. The most important findings are summarized in Figure 3; the current study found that hetacillin was noninferior to ceftiofur in the primary outcomes of bacteriological, pathogen, and clinical cures and secondary outcomes describing survival to 30 and $60 \mathrm{~d}$. Hetacillin was superior to ceftiofur when clinical days was dichotomized to less than or equal to $4 \mathrm{~d}$.

The overall bacteriological cure risk difference between the groups was -0.047 . Noninferiority could be stated when the $95 \%$ confidence interval $(-0.143$ to 0.048) falls above the noninferiority margin of -0.15 . When comparing gram-positive to -negative etiologies, a larger risk difference than for an overall comparison was seen in CM caused by gram-positive organisms. Upon further examination of the risk difference for gram-positive etiologies, it was noted that although numerically higher cure rates were observed for hetacillintreated CNS and hetacillin-treated Staph. aureus cows than the respective ceftiofur-treated cows, ceftiofur had higher cure rates in the more represented culture outcomes such as Strep. dysgalactiae (Figure 1). The bacteriological cure risk difference was lowest (least negative) for gram-negative etiologies, resulting from a numerically higher but nonsignificant cure rate for ceftiofur-treated E. coli and Klebsiella cows versus the respective hetacillin-treated cows. The confidence intervals of the risk differences for gram-positive and -negative etiologies cross both the noninferiority limit and zero, suggesting that we lacked the power to identify an observed difference smaller than our declared margin. This may have been due to the smaller sample size when culture results were separated by gram-negative and gram-positive status.

Despite the large difference seen in bacteriological cure of Strep. dysgalactiae CM between hetacillin- and ceftiofur-treated cows (ceftiofur having a greater cure), the rate of clinical cure by d 4 for this organism was greater for hetacillin-treated cows. The same could be seen for the gram-negative organisms, E. coli and Klebsiella spp.; despite a numerically greater bacteriological cure for ceftiofur, this drug had a lower percentage of clinical cures for these organisms as compared with hetacillin. Analysis of the binary outcome "clinical cure in less than 4 days" resulted in a positive risk difference of 0.119 ; a confidence interval beyond both the noninferiority limit, -0.15 , and zero indicates superiority of hetacillin over ceftiofur for this outcome (Figure 3). One could speculate that clinical cure rates may be higher for hetacillin cows due to bias; CS is a subjective measure and having to treat ceftiofur cows 2 additional days may have led observers to be more critical of symptoms before administration of medication. Blinding in regard to treatment was not performed in our trial, but producers and researchers were unaware 
of objective primary outcomes, including bacteriologic and pathogen cures and the quantitative secondary outcomes LS and milk production.

To obtain the power and numbers needed to evaluate CM treatment efficacy, trials that use bacteriological cure as a primary outcome must restrict treatment assignment to cases in which bacteria are isolated. This then determines the need to wait for culture results before administration of the product (Schukken and Deluyker, 1995). In the current study, we used a pathogen cure outcome, following and modifying the ideas outlined in Pinzón-Sanchez and Ruegg (2011) and Oliveira et al. (2013), to facilitate the inclusion of no growth results. This allows researchers to analyze the risk of remaining pathogen free. Our values of 43 and $45 \%$ for pathogen cure of ceftiofur- and hetacillin-treated cows, respectively, were lower than the $65 \%(\mathrm{n}=276 / 427)$ found by Oliveira et al. (2013; IMM treatment with any antimicrobial). Low values for pathogen cure may be due to the large number ( $\sim 25 \%)$ of Streptococcus spp.positive cows in the trial. Whereas the cure rate for CM caused by environmental streptococci may exceed $50 \%$, cows can suffer frequent relapses (Guterbock et al., 1993; Van Eenennaam et al., 1995; Morin et al., 1998). The delay of treatment may have affected these cows, as aggressive IMM treatment of Strep. uberis CM has been shown to result in cure rates that exceed $90 \%$ (Hillerton and Kliem, 2002).

Our average clinical days, 3.4 and 3.7 for hetacillin- and ceftiofur-treated cows, respectively, are lower than the ceftiofur-treated cows $(4.5 \mathrm{~d}, \mathrm{n}=262)$ and cephapirin-treated cows ( $4.9 \mathrm{~d}, \mathrm{n}=49)$ in a CM study performed by Oliveira and Ruegg (2014). Our results were also less than cephalosporin treated cows in an earlier study by Pinzón-Sanchez and Ruegg (2011; 5.4 $\mathrm{d}, \mathrm{n}=143)$. This is likely due to our assignment of 5 clinical days to those cows that exhibited clinical signs beyond the initial observation period. An additional study detected lower values than found in the present study for clinical days, at 2.7 and $3.2 \mathrm{~d}$ for blankettreated cephapirin and selectively treated cephapirin cows, respectively (Lago et al., 2011a). Despite these deviations from our findings, each study referenced concluded no statistical differences between treatment groups in days to clinical cure.

For extended clinical outcome comparisons, $92 \%$ of hetacillin-treated cows and $91 \%$ of ceftiofur-treated cows retained their cured statuses on d 14 and 21 postenrollment. This differs from the Schukken et al. (2013) study that found an overall clinical cure of $62 \%$ $(\mathrm{n}=184 / 296)$ at $\mathrm{d} 10$ and 17 . This may be due to the clinical scoring system in their study, which included rectal temperature, hydration scoring, and attitude assessment.
The model for postevent milk production included etiology as a significant variable. When the causative microorganism was absent on initial culture (a no growth result), cows responded with a significantly higher milk production than those with growth. Mastitis is associated with losses in milk production, particularly for coliform cases (Gröhn et al., 2004). Our data indicates that cows with $E$. coli average the greatest loss in milk production at next test day relative to other etiologies. Values were similar to a change of $-4.62 \mathrm{~kg}$ found by Gröhn et al. (2004) for cows 15 to 21 DIM. In the latter study, however, Klebsiella affected cows suffered the greatest loss, with an average change of $-6.24 \mathrm{~kg}$ of milk/d during this time period. Our differences may be reflective of the few numbers of Klebsiella cases or the various genetic strains found on 6 dairies (Gröhn et al., 2004).

Parity, previous LS, and etiology were significant in a model for postevent LS. Inclusion of these variables agreed with known risk factors associated with shortterm posttreatment outcomes (Pinzón-Sanchez and Ruegg, 2011). In regard to etiology, Staph. aureus cows experienced the highest postevent LS. This is supported by the fact that Staph. aureus is commonly cultured in dairies with high bulk tank SCC (Barkema et al., 1997). Treatment was not significant in the model. No comparisons have been described in recent literature between hetacillin and ceftiofur for posttreatment milk quality and quantity indices. However, Schukken et al. (2011) concluded no significant differences in SCC nor milk yield for the remainder of the lactation when considering ceftiofur-treated gram-negative cases and untreated gram-negative cases.

Noninferiority was described for hetacillin in both survival indices (Figure 3). Historically, the culling rate for $\mathrm{CM}$ cows was estimated to be more than twice that of non-CM cows; the risk of culling is highest in the period immediate to the mastitis event (Barkema et al., 1997; Gröhn et al., 2004). For this reason, we used a 60-d interval for event analysis, but expected to find similar results had we followed the cows for a longer period of time. Though this is the first trial comparing IMM hetacillin to ceftiofur, recent selective treatment trials have reported no statistical differences in removal from the herd within the weeks after CM when cows were treated with different cephalosporin products or protocols (Lago et al., 2011a,b). The costs of culling contribute to the total costs of $\mathrm{CM}$ and also influence the benefits returned from intensive antimicrobial treatments; knowledge of noninferiority of one product to another for survival indices is economically important (Steeneveld et al., 2011).

Milk yield was similarly significant in Cox proportional hazards analysis when assessing survival in the 
herd and time-to-next-mastitis in the same quarter. However, the recurrence risk of CM was not dependent on etiology in our analysis. Whereas this model agreed with a previous study performed by Lago et al. (2011b) in which the effect of organism was not significant, etiology was a sensitive indicator for recurrence risk in a streptococcal CM study (Van Eenennaam et al., 1995). The uneven distribution of Strep. uberis may have precluded the detection of an effect of etiology in survival analysis. Additionally, the larger percentage of these cows in the ceftiofur-treated group may introduce bias when assessing etiological analysis for each of the treatment outcomes, particularly if ceftiofur cows generally experience higher cure rates for this etiology.

The only significant difference between treatment groups was for hospital days, with a difference in least squares means of $1.8 \mathrm{~d}$, favoring hetacillin. This difference results from 2 less treatment days for hetacillin cows while maintaining the same 72-h milk withhold for each product. Within the design of the study, although milk withhold times were the same, treatment duration protocols for the drugs were not identical. Based on a recent Wisconsin study, which characterized an average duration for IMM ceftiofur use between 4 and $5 \mathrm{~d}, 5 \mathrm{~d}$ was selected for treatment length in this trial (Oliveira and Ruegg, 2014). We felt that selection of this duration (1) reflected current farm use and (2) permitted ceftiofur the best chance to display better efficacy over hetacillin. The hetacillin label indication dictated the 3 -d treatment period for this drug. Although the difference may be evident to readers, as producers are simply following the pasteurized milk ordinance, we were unable to assume that hetacillin- nor ceftiofur-treated cows would experience unresolved clinical signs beyond the withhold date without actually testing it. Cows in the study remained in the hospital pen until their milk was no longer violative and symptoms of CM were resolved. Initial study design considered that clinical days may have been a more important factor in hospital day analysis than both the withhold and treatment durations. An economic analysis for hetacillin treatment in regards to decreased labor costs and increased days of saleable milk was not performed.

When assessing severity of CM, approximately $14 \%$ of cows did not qualify due to systemic signs. This was similar to the $15.3 \%$ value found in a survey of 50 Wisconsin dairy farms (Oliveira et al., 2013), but higher than values found on a smaller survey $(8 \%, \mathrm{n}=$ $266)$ and in a recent Canadian survey $(10 \%, \mathrm{n}=2,311$; Olde Riekerink et al., 2008; Pinzón-Sanchez and Ruegg, 2011). Exclusion of severe CM cows limits the generalizability of our results to cows with nonsevere mastitis. Due to individualized farm-specific treatment for severe mastitis, additional trials would need to be performed to assess differences in the 2 antibiotic products.

\section{CONCLUSIONS}

A CM trial comparing a 5-d treatment with ceftiofur to a 3-d treatment with hetacillin showed noninferiority of the latter in regards to bacteriological cure, clinical cure, pathogen cure, and survival to 30 and $60 \mathrm{~d}$. When noninferiority analysis was applied to gram-positive and -negative etiological groups, the data were inconclusive. However, results are consistent with the fact that these 2 IMM products are effective against 1 or more gram-positive organisms as well as gram-negative E. coli. No statistically significant differences in continuous outcomes such as clinical days, postevent milk yields, and postevent LS were found between treatment groups. Hospital days differed favorably for hetacillin versus ceftiofur, allowing milk from hetacillin-treated cows to contribute to the bulk tank $1.8 \mathrm{~d}$ earlier than the respective ceftiofur-treated cows. No effect of treatment was observed on risk of leaving the herd in $60 \mathrm{~d}$ or on risk of experiencing a new mastitis event in the same quarter. Differences in bacteriological cure profiles, however, determine the importance of pretreatment diagnostics. Farms with access to culture results may benefit most from our results. Our findings can aid in herd-specific decisions, specifically in developing treatment protocols for nonsevere CM.

\section{ACKNOWLEDGMENTS}

We acknowledge the technicians, couriers, and veterinarians of Quality Milk Production Services laboratories as well as Lauren Pitman of Dairy Health and Management Services (Lowville, NY) for their help with cultures, study design, monitoring, and sample retrieval. Financial support for this study was provided in part by Boerhinger Ingelheim Vetmedica Inc. (St. Joseph, MO). We thank the participating farm owners and staff for their roles in enrollment and treatment.

\section{REFERENCES}

Ali, A. K. A., and G. E. Shook. 1980. An optimum transformation of somatic cell concentration in milk. J. Dairy Sci. 63:487-490.

Arruda, A. G., S. Godden, P. Rapnicki, P. Gorden, L. Timms, S. S. Aly, T. W. Lehenbauer, and J. Champagne. 2013. Randomized noninferiority clinical trial evaluating 3 commercial dry cow mastitis preparations: I. Quarter-level outcomes. J. Dairy Sci. 96:4419-4435.

Barkema, H. W., Y. H. Schukken, T. J. Lam, D. T. Galligan, M. L. Beiboer, and A. Brand. 1997. Estimation of interdependence among quarters of the bovine udder with subclinical mastitis and implications for analysis. J. Dairy Sci. 80:1592-1599. 
Baynes, R. E., and J. E. Riviere. 2014. Strategies for Reducing Drug and Chemical Residues in Food Animals: International Approaches to Residue Avoidance, Management, and Testing. John Wiley \& Sons Inc., Hoboken, NJ.

Dohoo, I. R., J. Smith, S. Andersen, D. F. Kelton, and S. Godden. Mastitis Research Workers' Conference. 2011. Diagnosing intramammary infections: Evaluation of definitions based on a single milk sample. J. Dairy Sci. 94:250-261.

Food and Drug Administration (FDA). 2010. NADA 055-054. Federal Food, Drug and Cosmetic Act 21CFR part 514. Section 512(c)(2) (F)(ii). FDA, Washington, DC.

Food and Drug Administration (FDA). 2005. NADA 141-238. Federal Food, Drug and Cosmetic Act 21CFR part 514. Section 512(c)(2) (F)(ii). FDA, Washington, DC.

Gröhn, Y. T., D. J. Wilson, R. N. Gonzalez, J. A. Hertl, H. Schulte, G. Bennett, and Y. H. Schukken. 2004. Effect of pathogen-specific clinical mastitis on milk yield in dairy cows. J. Dairy Sci. $87: 3358-3374$

Guerín-Faublee, V., G. Carret, and P. Houffschmitt. 2003. In vitro activity of 10 antimicrobial agents against bacteria isolated from cows with clinical mastitis. Vet. Rec. 152:466-471.

Guterbock, W. M., A. L. Van Eenennaam, R. J. Anderson, I. A. Gardner, J. S. Cullor, and C. A. Holmberg. 1993. Efficacy of intramammary antibiotic therapy for treatment of clinical mastitis caused by environmental pathogens. J. Dairy Sci. 76:3437-3444.

Hillerton, J. E., and K. E. Kliem. 2002. Effective treatment of Streptococcus uberis clinical mastitis to minimize the use of antibiotics. J. Dairy Sci. 85:1009-1014.

Hornish, R. E., and S. F. Kotarski. 2002. Cephalosporins in veterinary medicine - Ceftiofur use in food animals. Curr. Top. Med. Chem. $2: 717-731$.

Johnson, A. P., S. M. Godden, E. Royster, S. Zuidhof, B. Miller, and J. Sorg. 2016. Randomized noninferiority study evaluating the efficacy of 2 commercial dry cow mastitis formulations. J. Dairy Sci. 99:593-607.

Lago, A., S. M. Godden, R. Bey, P. L. Ruegg, and K. Leslie. 2011a. The selective treatment of clinical mastitis based on on-farm culture results: I. Effects on antibiotic use, milk withholding time, and short-term clinical and bacteriological outcomes. J. Dairy Sci. 94:4441-4456.

Lago, A., S. M. Godden, R. Bey, P. L. Ruegg, and K. Leslie. 2011b. The selective treatment of clinical mastitis based on on-farm culture results: II. Effects on lactation performance, including clinical mastitis recurrence, somatic cell count, milk production, and cow survival. J. Dairy Sci. 94:4457-4467.

Lindquist, D. A., R. E. Baynes, and G. W. Smith. 2015. Short communication: Pharmacokinetics of intramammary hetacillin in dairy cattle milked 3 times per day. J. Dairy Sci. 98:1856-1861.

Morin, D. E., R. D. Shanks, and G. C. McCoy. 1998. Comparison of antibiotic administration in conjunction with supportive measures versus supportive measures alone for treatment of dairy cows with clinical mastitis. J. Am. Vet. Med. Assoc. 213:676-684.

National Mastitis Council. 1999. Laboratory Handbook on Bovine Mastitis. National Mastitis Council Inc., Madison, WI.
Olde Riekerink, R. G., H. W. Barkema, D. F. Kelton, and D. T. Scholl. 2008. Incidence rate of clinical mastitis on Canadian dairy farms. J. Dairy Sci. 91:1366-1377.

Oliveira, L., C. Hulland, and P. L. Ruegg. 2013. Characterization of clinical mastitis occurring in cows on 50 large dairy herds in Wisconsin. J. Dairy Sci. 96:7538-7549.

Oliveira, L., and P. L. Ruegg. 2014. Treatments of clinical mastitis occurring in cows on 51 large dairy herds in Wisconsin. J. Dairy Sci. 97:5426-5436.

Pfeifer, Y., A. Cullik, and W. Witte. 2010. Resistance to cephalosporins and carbapenems in gram-negative bacterial pathogens. Int. J. Med. Microbiol. 300:371-379.

Piaggio, G., D. R. Elbourne, D. G. Altman, S. J. Pocock, and S. J. W. Evans. 2006. Reporting of non-inferiority and equivalence randomized trials: An extension of the CONSORT statement. JAMA 295:1152-1160.

Pinzón-Sanchez, C., and P. L. Ruegg. 2011. Risk factors associated with short-term post-treatment outcomes of clinical mastitis. J. Dairy Sci. 94:3397-3410.

SAS Institute. 2014. SAS User's Guide. Version 9.4 SAS Institute Inc., Cary, NC.

Schukken, Y. H., G. J. Bennett, M. J. Zurakowski, H. L. Sharkey, B. J. Rauch, M. J. Thomas, B. Ceglowski, R. L. Saltman, N. Belomestnykh, and R. N. Zadoks. 2011. Randomized clinical trial to evaluate the efficacy of a 5-day ceftiofur hydrochloride intramammary treatment on nonsevere gram-negative clinical mastitis. J. Dairy Sci. 94:6203-6215.

Schukken, Y. H., and H. A. Deluyker. 1995. Design of field trials for the evaluation of antibacterial products for therapy of bovine clinical mastitis. J. Vet. Pharmacol. Ther. 18:274-283.

Schukken, Y. H., M. J. Zurakowski, B. J. Rauch, B. Gross, L. L. Tikofsky, and F. L. Welcome. 2013. Noninferiority trial comparing a first-generation cephalosporin with a third-generation cephalosporin in the treatment of nonsevere clinical mastitis in dairy cows. J. Dairy Sci. 96:6763-6774.

Steeneveld, W., T. van Werven, H. W. Barkema, and H. Hogeveen. 2011. Cow-specific treatment of clinical mastitis: An economic approach. J. Dairy Sci. 94:174-188.

Van Eenennaam, A. L., I. A. Gardner, J. Holmes, L. Perani, R. J. Anderson, J. S. Cullor, and W. M. Guterbock. 1995. Financial analysis of alternative treatments for clinical mastitis associated with environmental pathogens. J. Dairy Sci. 78:2086-2095.

Walker, E., and A. S. Nowacki. 2011. Understanding equivalence and noninferiority testing. J. Gen. Intern. Med. 26:192-196.

Wenz, J. R., G. M. Barrington, F. B. Garry, R. P. Dinsmore, and R. J. Callan. 2001. Use of systemic disease signs to assess disease severity in dairy cows with acute coliform mastitis. J. Am. Vet. Med. Assoc. 218:567-572.

Wilson, D. J., R. N. Gonzalez, K. L. Case, L. L. Garrison, and Y. T. Gröhn. 1999. Comparison of seven antibiotic treatments with no treatment for bacteriological efficacy against bovine mastitis pathogens. J. Dairy Sci. 82:1664-1670. 